\title{
الفقه : دراسة فكرية إسلامية
}

Muh Barid Nizarudin Wajdi

STAI Miftahul Ula Nganjuk

baridnizar84@gmail.com

\section{ABSTRACT}

Scholars argue that in the Islamic law there are all laws that govern all human behavior, both word and deed. These laws are sometimes stated explicitly and strictly and sometimes only in the form of arguments and rules in general. To understand Islamic law in the form of the first one is not necessary ijtihad, but simply taken and practiced as it is, because it is clearly and explicitly called by Allah. Islamic law in this form is called pure revelation. As for the knowledge of Islamic law in the second form, it is necessary for the sincere efforts of the mujtahids to dig into the law contained in the nash through careful study and understanding; The whole law set forth in this manner is called fiqih.

Keyword : Fiqh, Dirosah Fikriyah, Dirosah Islamiyah

خلفية المشكلة

يوافق العلماء على أنه توجد فى الشريعة الإسلامية جميع القوانين التى تحكم جميع الأعمال البشرية من الأقوال والأفعال.

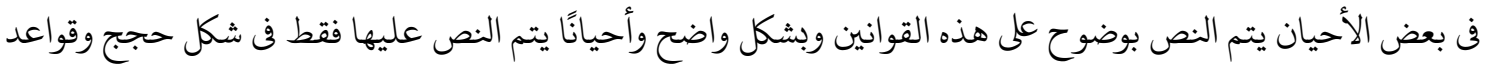

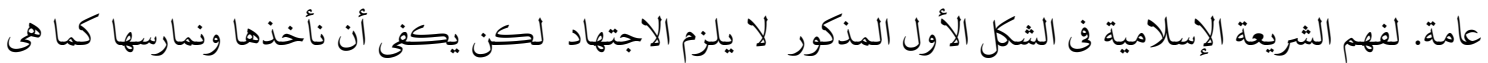
لأنها تسىى بوضوح وصراحة من قبل الله. يسمى الشريعة الإسلامية فى هذا الشكل الوحى الخالص. أما بالنسبة إلى معرفة لإنة

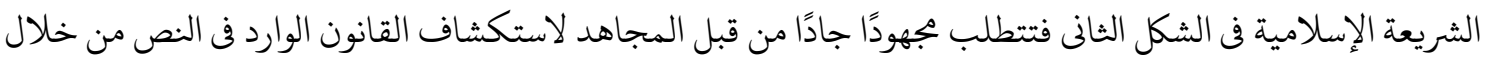

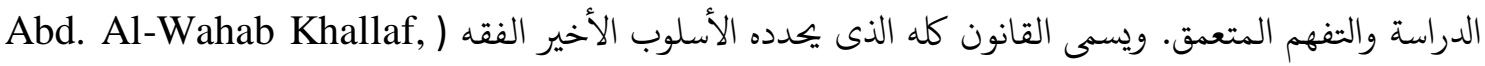

لذلك نحاول ككتاب شرح كيفية دراسة الفكر الإسلامى فيما يتعلق بالفقه. ما سيتم شرحه أكثر فى الورقة التالية.

صياغة المشكلة من خلال النظر إلى الخلفية التى أثيرت فإن بعض القضايا الرئيسية التى يمكن للكاتب أن يصاغها وستناقش فى هذه الورقة العلمية هييتم

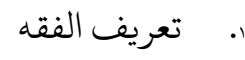

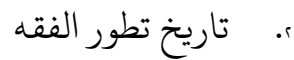

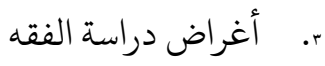

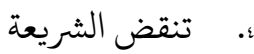
ـ. القوانين السورية 


\section{Edutec}

Journal of Education And Technology

\section{التحليل \\ | (أ. أ. تعريف الفقه}

من منظور اللغة يأتى الفقه من كلمة" الفقهاء "التى تعنى" الفهم "و" الفهم ."فى الدصطلحات يقصد بعلم الفقه كعلم

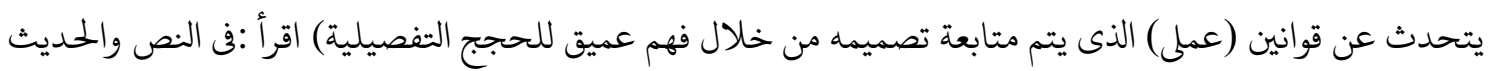
(hasbi, 1967) الفقه وفق اللغة العربية فهم. وفقا للمصطلح هو علم معرفة قوانين والتى فى أعمال أعضاء مأخوذة من تفسيراتهم بالثفيل (Sulaiman. 2002) الفقه أو الفقه (عربي: السرير) هو واحد من مجالات العلوم في الشريعة الإسلامية التى تتناول على وجه التحديد القضايا

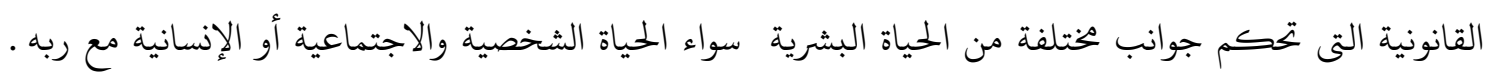
(wikipedia) الشريعة الإسلامية المقصود في التعريف أعلاه هو جميع الإجراءات التى يتم منحها القانون نفسه والتى يتم أخذها من

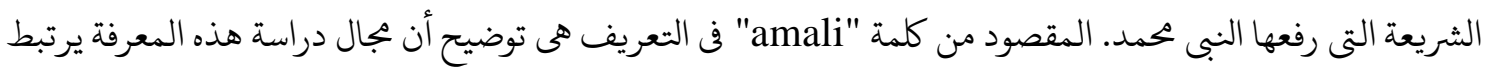

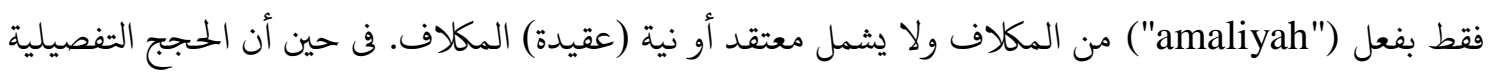

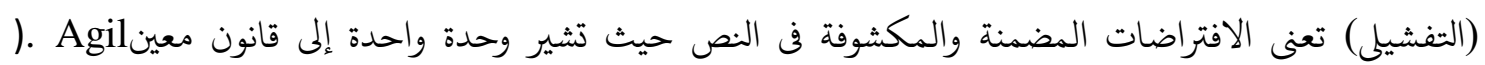

(man Munawwar في إصدار آخر يشار أيضًا إلى الفقه القانونى باعتباره مجموعة من قوانين الشريعة المتعلقة بممارسة المكلاف مأخوذة

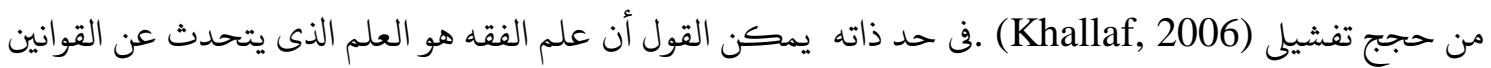
كما هو مذكور أعلاه.

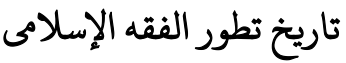

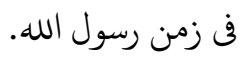

قال رسول اله. خلال حياته أصبح مرجعًا لكل مسلم لمعرفة قانون دينه. كلا الشريعة مأخوذة من القرآن ومن السات السنة.

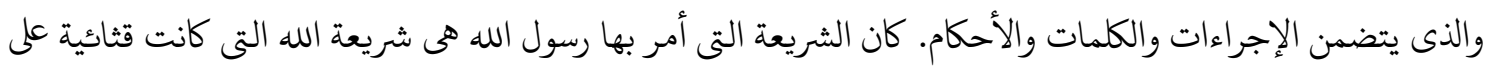

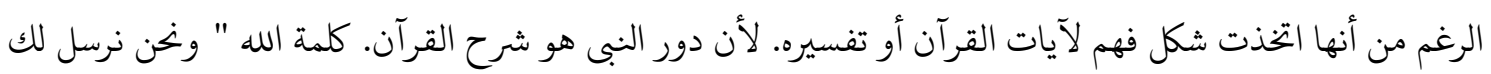

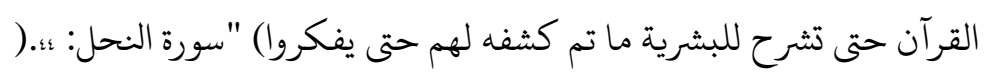

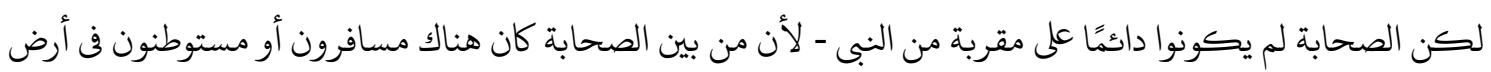

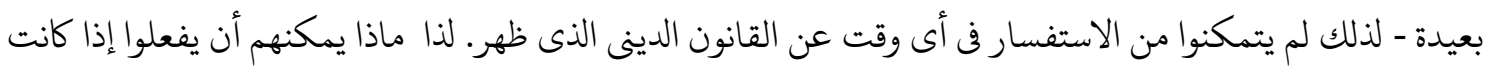

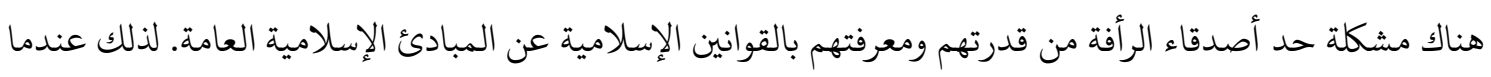

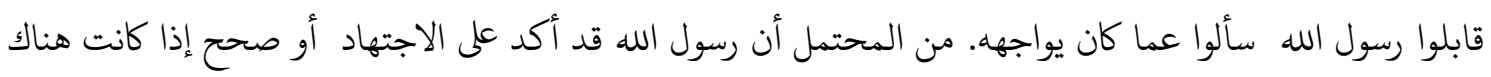
أخطاء. لكن النبى لم يرفض أبداً مبادئ الاجتهاد. 


\section{Edutec}

Journal of Education And Technology

2597-9221 (Online)

على سبيل المثال خبرة عمار بن ياسر. قال عمار بن ياسر را" لقد أرسلنى رسول اله لأداء مهمة ثم قمت بالحنين ولم

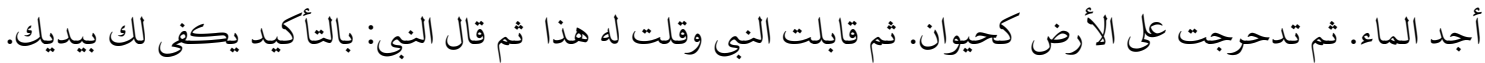
ثم ضرب النبى يده على الأرض بفات واحد ثم فرك يده اليسرى على يده اليمنى ظهر يده ووجهه)" .رواه آسى شيخاني

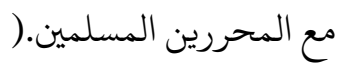

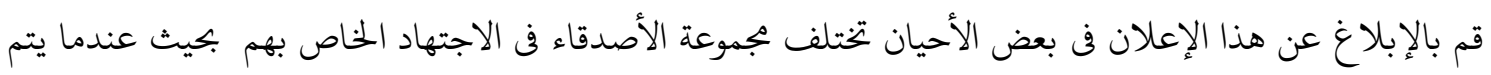

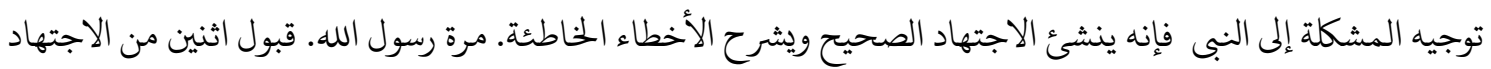

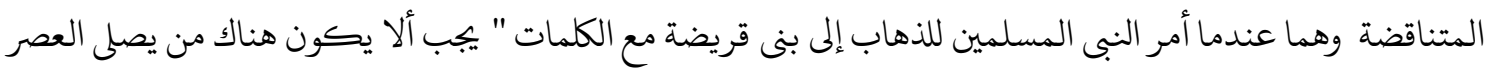

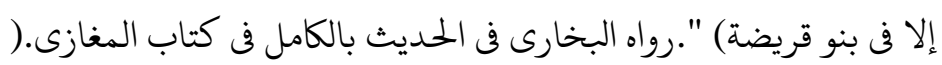

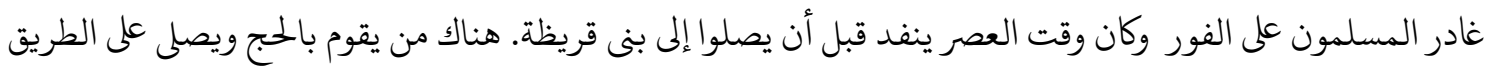

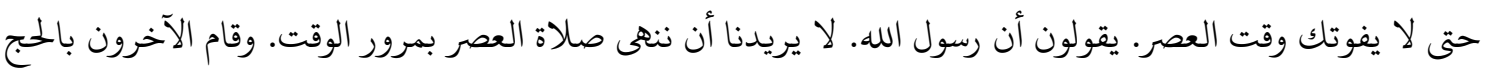

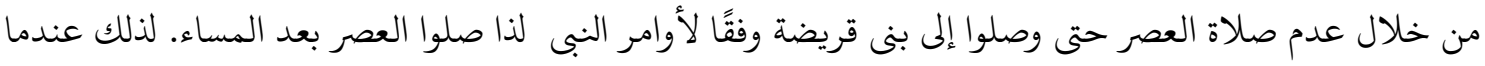

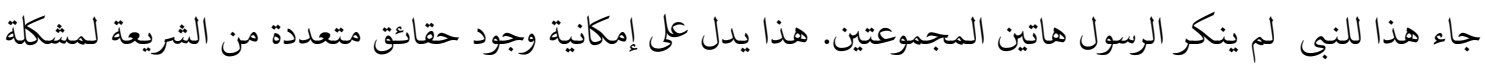

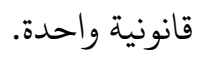

$$
\text { من وفاة النبى إلى وفاة أثمة المدرسة الأربعة }
$$

بعد رسول الله. الموت ومناطق جديدة من الإسلام شاسعة بدأت الحاجة إلى اجتهاد الأصدقاء زيادة حادة. سبب ذلك

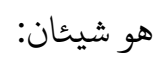

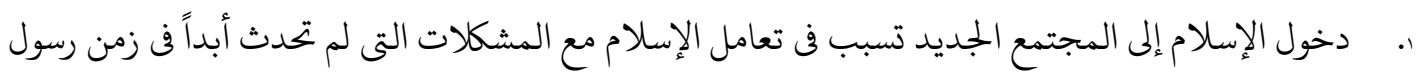

$$
\text { اله ولم ينزل الوحى وكانت هناك حاجة لمعرفة الشريعة الدينية وتفسيرها. }
$$

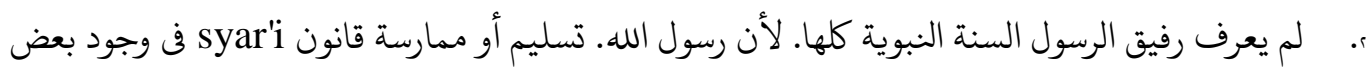

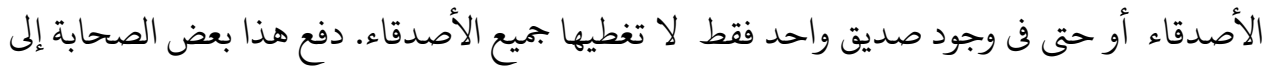

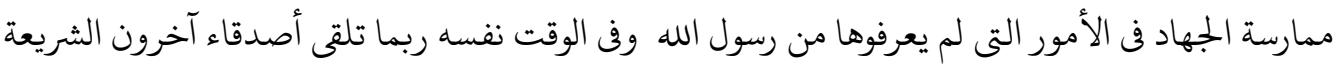

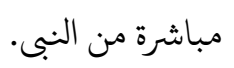

المسافة بين الأصدقاء الذين كانوا متباعدين بعد وفاة عمر بن الخطاب رع فتحت المجال لظهور مدرستين مختلفتين

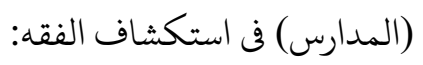

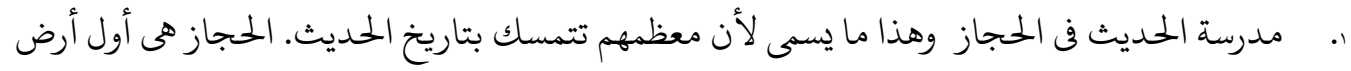

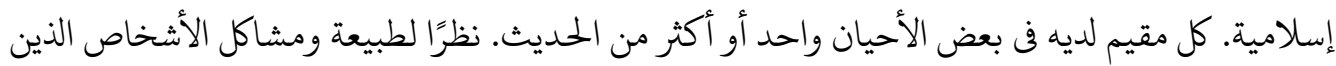
لا يواجهون الكثير من التغيير فلا تحتاج إلى الاجتهاد. 


\section{Edutec}

Journal of Education And Technology

2597-9221 (Online)

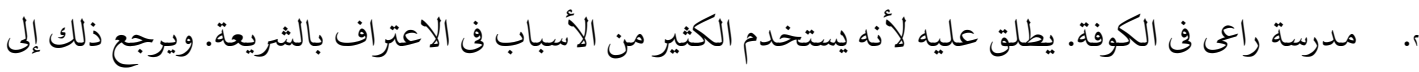

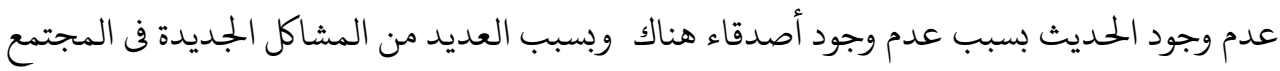
الجديد التى لا أساس لها على الإطلاق.

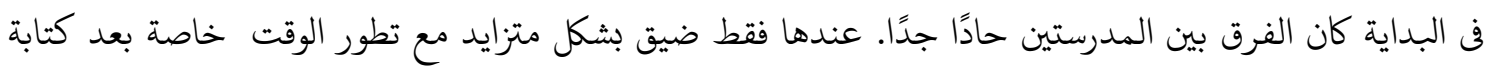

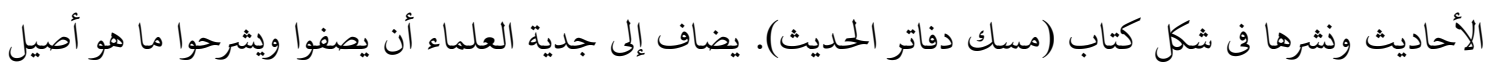

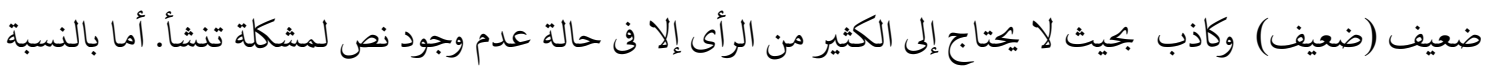

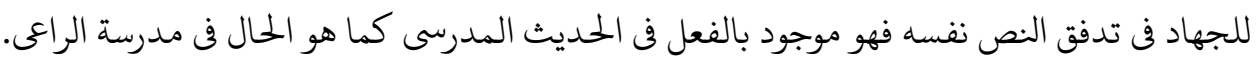

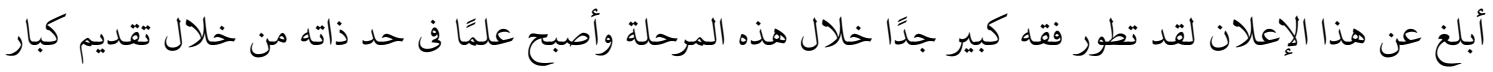

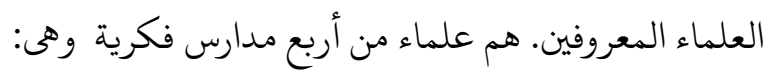

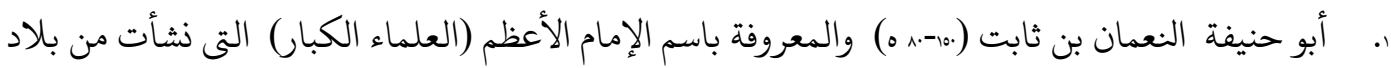

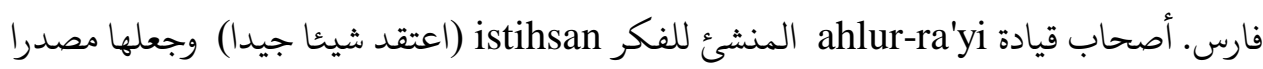
للشريعة الإنلامية. له مدرسة حنفى من الفكر أمر.

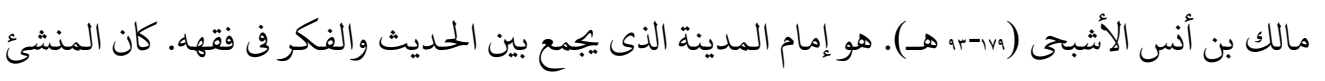

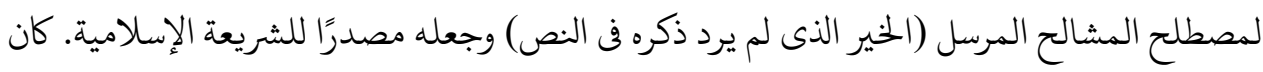

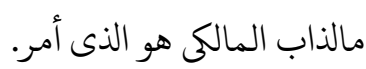

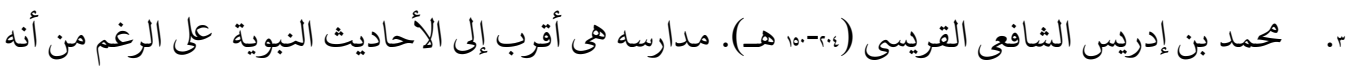

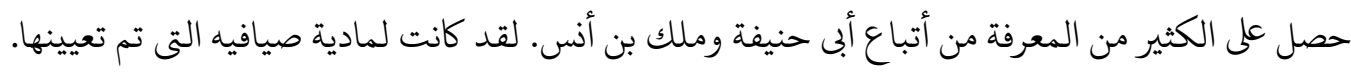

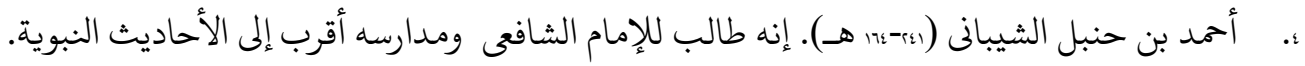

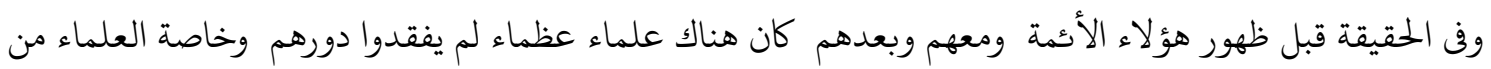

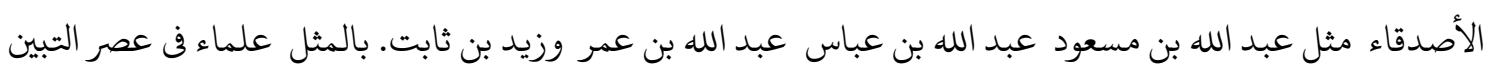

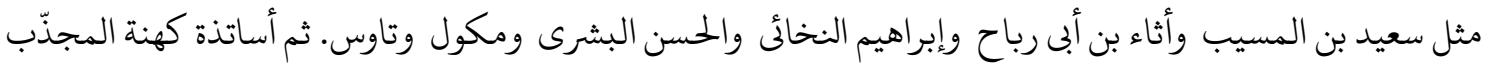

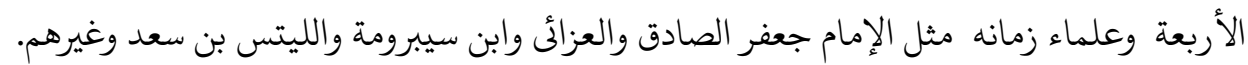

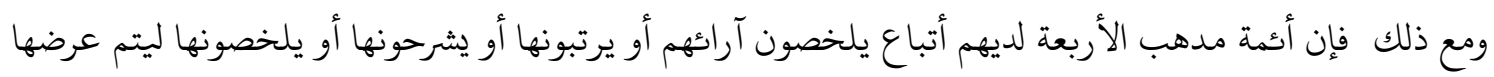

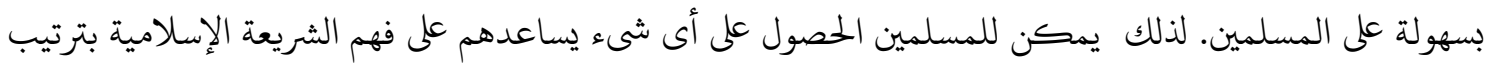

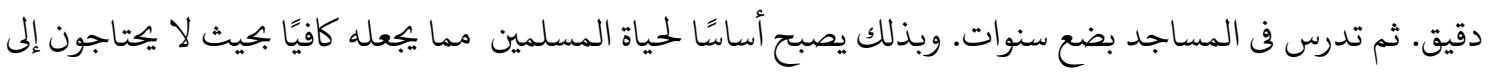

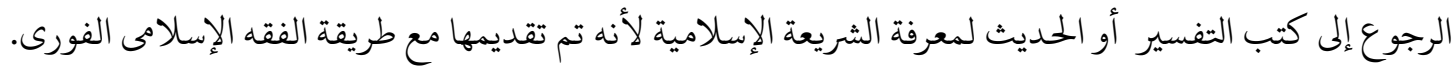

منذ وفاة أثمة مدهب الأربعة حتى انهيار الخلافة العثمانية

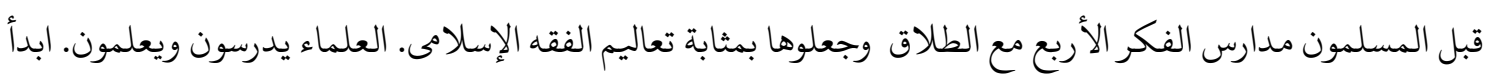

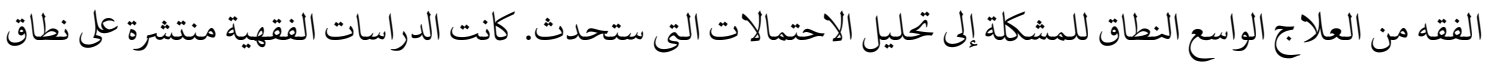




\section{Edutec}

Journal of Education And Technology

2597-9221 (Online)

واسع وبدأ متعصب المدح في الظهور وهو ما جعل أتباع المدرسة يعتبرون أنفسهم إسلامًا والذى شكل منه في البداية

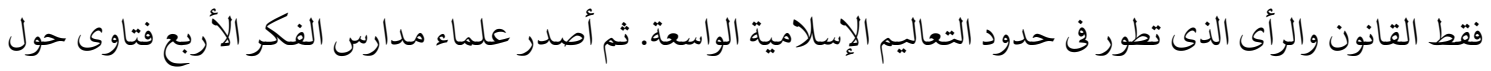

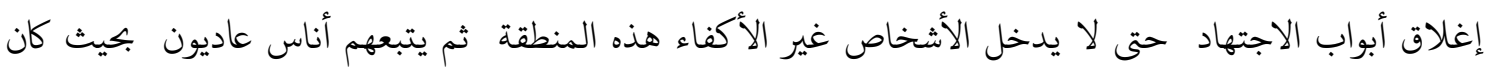

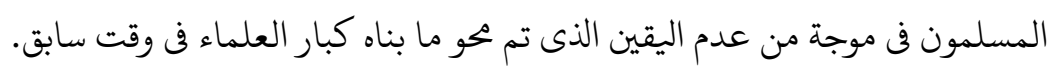

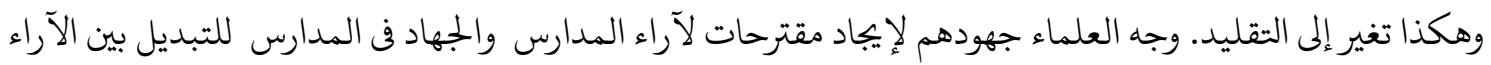

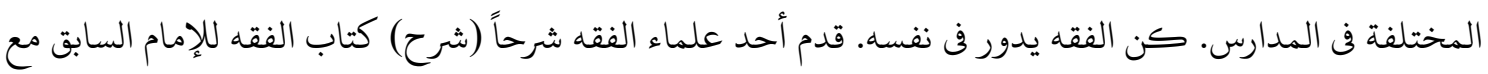

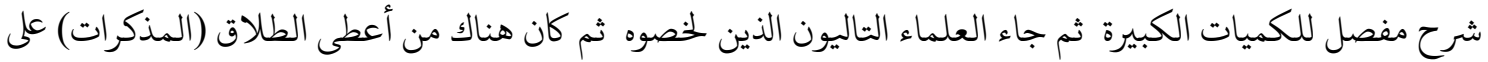

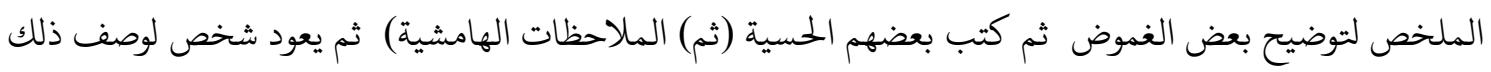

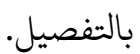
هكذا يواجه الفقه قسوة وصف الواقع القائم. كان هناك تورم فى دراسة العبادة في حين أن مشاكل السياسة الإسلامية

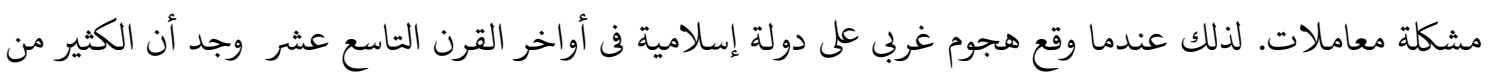

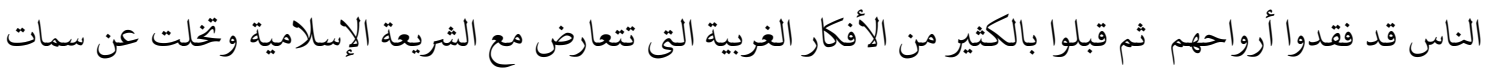

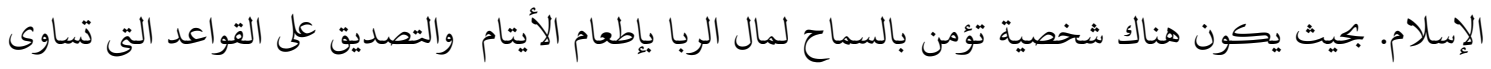
حقوق الرجال والنساء في الحصول على الميراث.

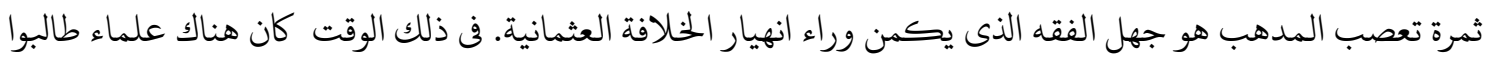

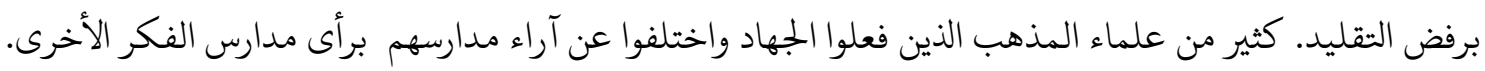

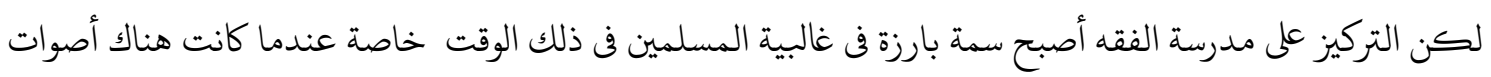

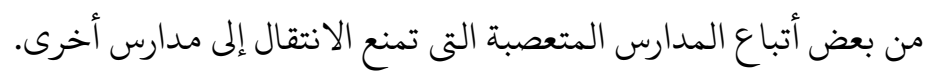

منذ سقوط الخلافة العثمانية حتى اليوم هذه

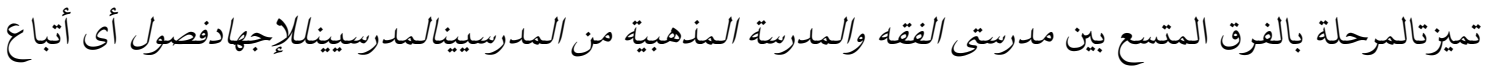

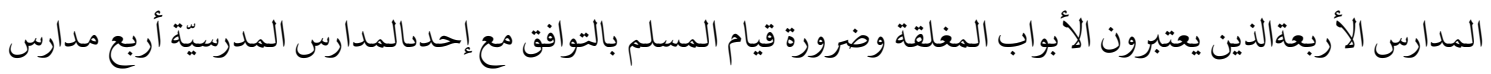
فكرية. المدرسة السلفية المدرسة التى تريد العودة مباشرة إلى القرآن والسنة تحرم من التقليد المسلم في أمور الفورو تتطلب

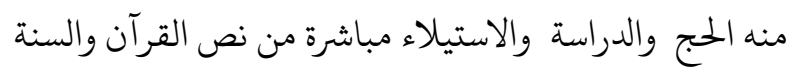

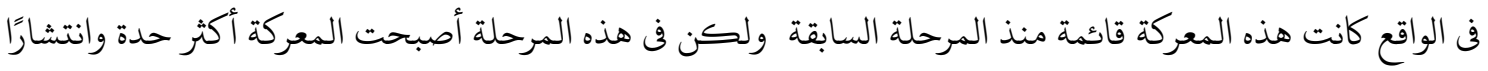

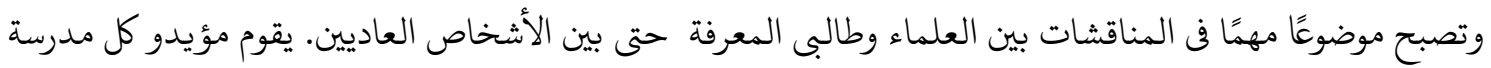
بكتابة الكتب وتوزيع المقالات لدعم آرائهم. 


\section{Edutec}

Journal of Education And Technology

2597-9221 (Online)

اتفق المسلمون على أن المرجع الأساسى لكل مسلم لاستكشاف الشريعة الإسلامية هو كتاب الله وسنة الرسل. تحدث

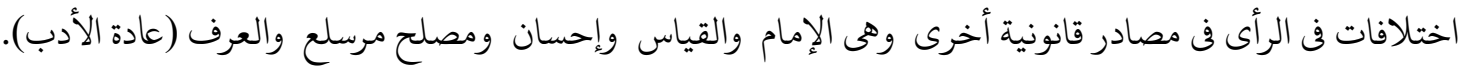

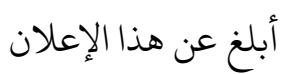

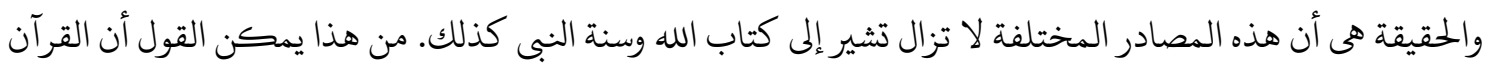

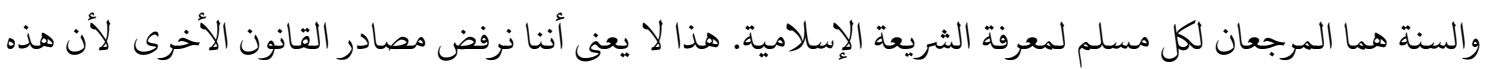
المصادر القانونية الأخرى تشير أيضًا إلى القرآن والسنة.

دراسة موضوع الفقه

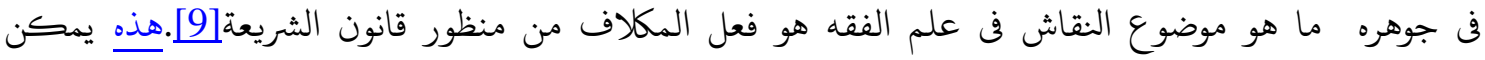
تصنيفالإجراءات في ثلاث مجموعات واسعة: العبادة والمعاملة والعقبة.

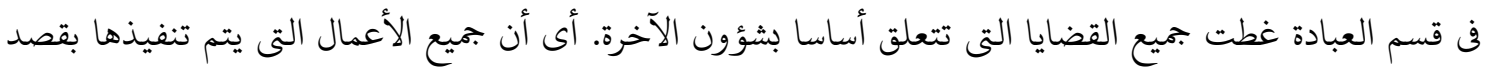
التقرب من الله مثل الصلاة والصوم والحج وما إلى ذلك.

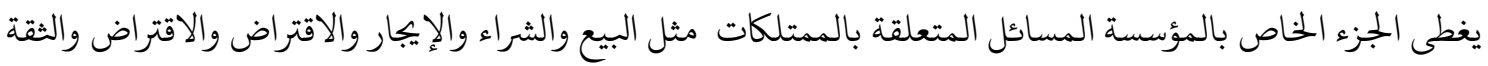
والميراث. في هذا القسم تضمنت أيضا مشكلة منخات وسياسا.

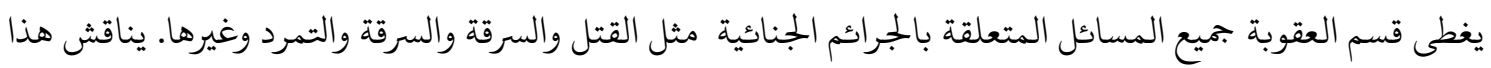
القسم أيضًا العقوبات مثل القصاص و الحديث القيث و الديات و الثعزير. ثم إذا تم فحصها بعناية يمكن تقسيم موضوع التعات مناقشة الفقه إلى الأقسام الثمانية التالية:

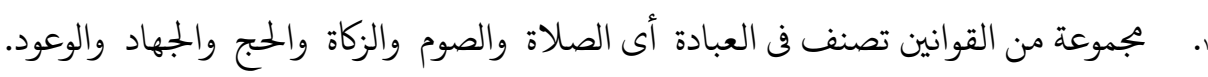

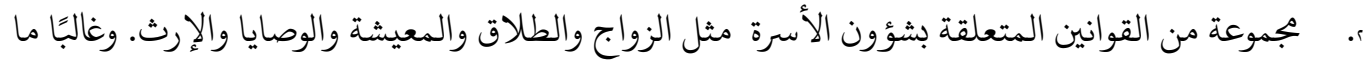

$$
\text { تسىى قوانين كهذه بالأحوال السياسية. }
$$

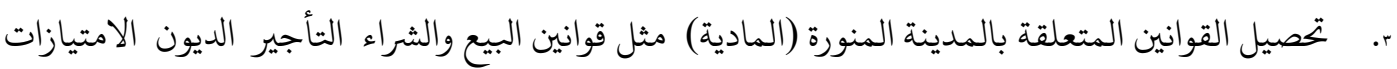
السيولة الحيالة المضاربة الوفاء بالعقود أو المعاملات والوفاء بالولاية.

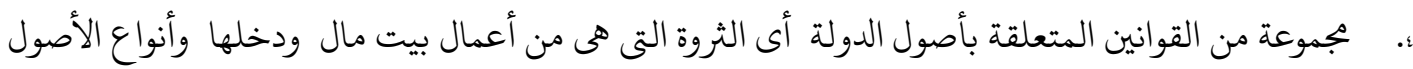
الموضوعة فن بيتول مول وأماكن الإنفاق. ينتىى هذا القانون إلى السياسة.

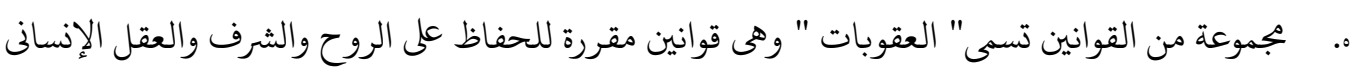
مثل القياس. - مثن. ". يجموعة من القوانين التى يتم تضمينها في القانون الإجرائى وهى القوانين المتعلقة بالعدالة والدعاوى القضائية والإثبات وما إلى ذلك. 


\section{Edutec}

Journal of Education And Technology

•. مجموعة من القوانين التى تنتى إلى القانون الدستورى مثل شروط كونه رئيس الدولة وحقوق السلطات فى

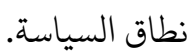

^. مجموعة من القوانين التى يشار إليها الآن باسم القانون الدولى. ويشمل ذلك قوانين الحرب الأسرى الاستيلاء السلام اتفاقات الفدية طرق ربط أهل الزمة إلخ .وهذا مدرج أيضًا في نطاق السياسة. الإبلاغ عن هذا الإعلان

لذلك يهدف الفقهاء في مناقشة ممارسات المكلّف أعلاه إلى معرفة القانون (الشرعى) لكل من هذه الإجراءات .

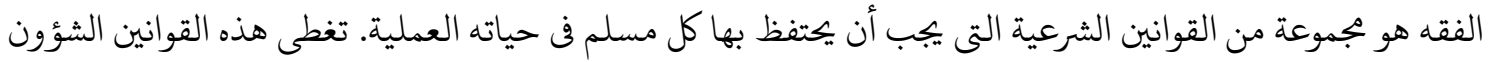

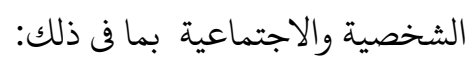

ا. الإلباضية " وهو القانون المتعلق بالصلاة والحج والزكاة. ×. الأحوال الصحية القانون المتعلق بالأسرة من البداية إلى النهاية.

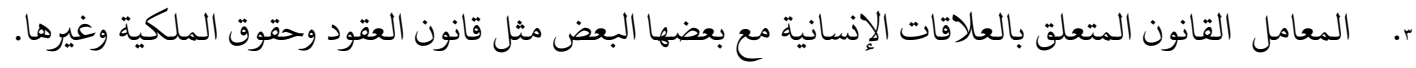

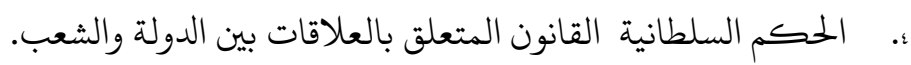
• أحكموس سلمى والحربي الذى ينظم العلاقات بين الدول.

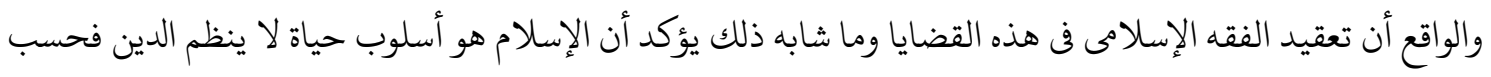
بل يككم البلاد أيضًا.

\section{أنواع القوانين السورية: القوانين السورية

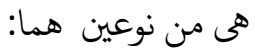
1. الكلثى مجموعة من القوانين التى أظهرها القرآن والسنة مع الاستنتاجات التى هى qath'iy ( بالتأكيد) مثل:

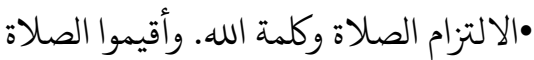

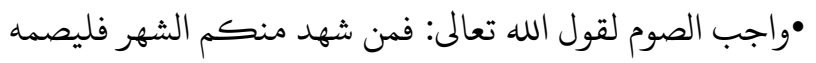
•الالتزام الزكاة كلمة اله: وآتوا الزكاة:

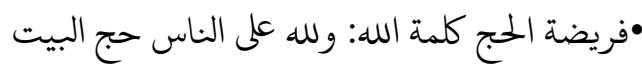

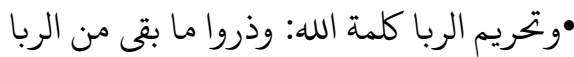

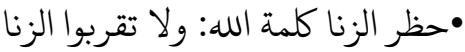

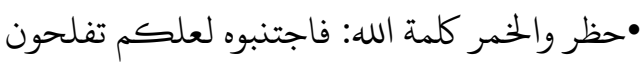

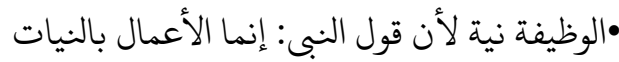

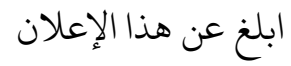




\section{Edutec}

Journal of Education And Technology

ليس لهذا القانون السريانى الذى هو قطى أى فرصة لإقامة الخلافة بين المسلمين على مستوى العلماء والمذاهب والأمة

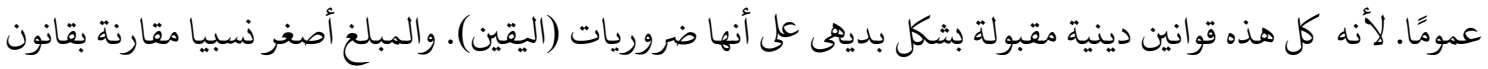
الزناى.

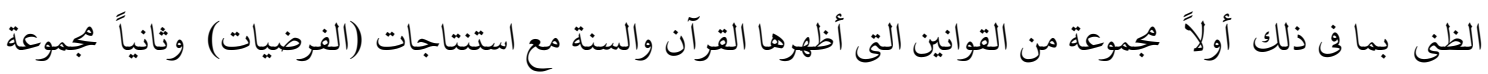

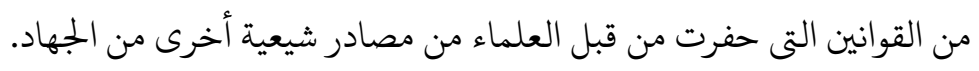

”. علم الفقه هو العلم الذى يتحدث عن قوانين السالى العمالى (العملى) الذى يتم متابعة تصميمه من خلال

$$
\begin{aligned}
& \text { فهم عميق لحججه الثفصيلية (اقرأ: الطفشيلى) في النصوص (القرآن والنين الحديث). }
\end{aligned}
$$

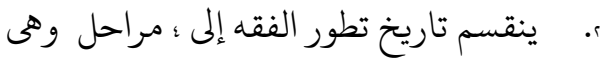

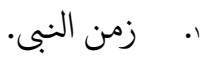

$$
\begin{aligned}
& \text { · منذ وفاة النبى حتى الموت من مدرسة الإمام أربعة }
\end{aligned}
$$

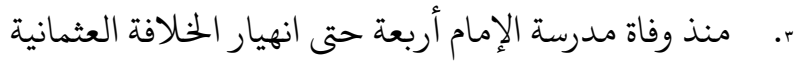

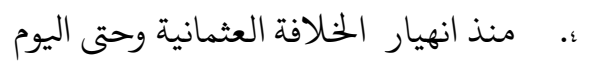

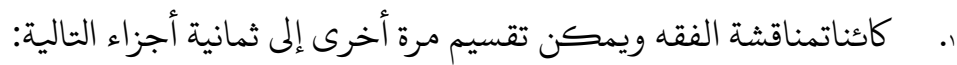

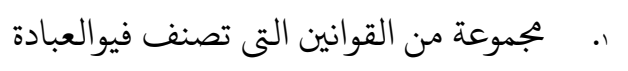$$
\text { . . مجموعة من القوانين المتعلقة بمسائل الأسرة }
$$$$
\text { r. مجموعة من القوانين المتعلقة بالمدينة المنورة (مادة) }
$$

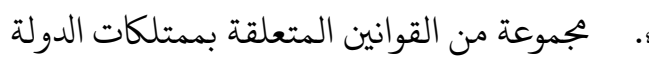

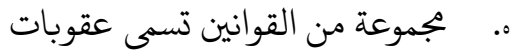

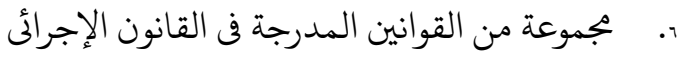

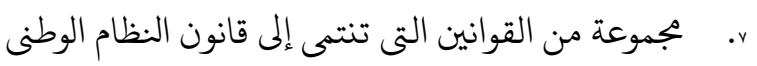

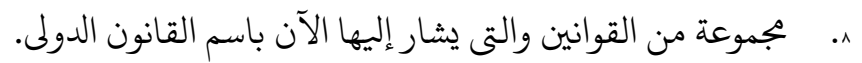

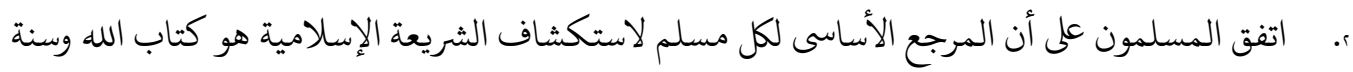

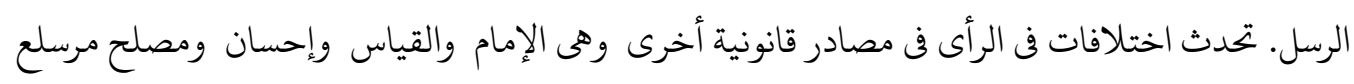

$$
\text { والعرف (عادة الأدب). }
$$

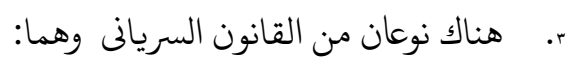

·. الكاثى وهو مجموعة من القوانين التى أظهرها القرآن والسنة مع استنتاج الكاثى (المحدد). 


\section{Edutec}

Journal of Education And Technology

$$
\begin{aligned}
& \text { •. زانى يتضمن أولاً مجموعة من القوانين التى أظهرها القرآن والسنة مع استنتاجات تشانى }
\end{aligned}
$$

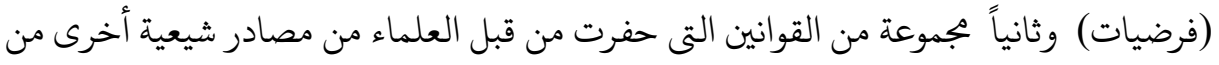

$$
\begin{aligned}
& \text { الجهاد. }
\end{aligned}
$$

المراجع

Khallaf, Abd. Al-Wahab, 1972. Ilmu Ushul Fiqih, Al-Majelis al a'la al Indonesia li AlDakwah al-Islamiyah, Jakarta.

Shiddiqy, Hasbi As, 1967, Pengantar Ilmu Fiqih, CV. Mulia, Jakarta.

Karim, A. Syafi'I, 2006, Fiqih dan Ushul Fiqih, CV. Pustaka setia, Bandung.

Rasjid, Sulaiman. 2002. Fiqh Islam. Bandung : Sinar Baru Algesindo

Al Qur'an dan Terjemahan. 2003. Bandung : CV. Diponegoro.

www.dakwatuna.com

http://www.wikipedia.com 